Article

\title{
Unraveling Public Good Games
}

\section{Pablo Brañas-Garza ${ }^{1}$ and Maria Paz Espinosa ${ }^{2, *}$}

1 GLOBE, Universidad de Granada, Granada 18071, Spain; E-Mail: pbg@ugr.es

2 BRIDGE, Universidad del País Vasco, Bilbao 48015, Spain

* Author to whom correspondence should be addressed; E-Mail: mariapaz.espinosa@ehu.es; Tel. +34-94-6013781; Fax: +34-94-6017123.

Received: 23 September 2011; in revised form: 9 November 2011 / Accepted: 11 November 2011 / Published: 21 November 2011

\begin{abstract}
This paper provides experimental evidence on how players predict end-game effects in a linear public good game. Our regression analysis yields a measure of the relative importance of priors and signals on subjects' beliefs on contributions and allows us to conclude that, first, the weight of the signal is relatively unimportant, while priors have a large weight and, second, priors are the same for all periods. Hence, subjects do not expect end-game effects and there is very little updating of beliefs. We argue that the sustainability of cooperation is related to this pattern of belief formation.
\end{abstract}

Keywords: public good games; end-game effects; beliefs; experiments

\section{Motivation}

Previous experimental research on public good games has shown that contributions are relatively high in one-shot games (40\%-60\% of endowment) and they fall over time in finitely repeated public good games (see Davis and Holt [1], Isaac, McCue and Plott [2], Kim and Walker [3], Ledyard [4]). Deviations from the free-riding zero contribution outcome and the decline over time have been rationalized through social preferences, learning effects, strategic considerations or conditional cooperation. ${ }^{1}$ Binmore [14] offers an explanation based on social norms. In the case of inexperienced

\footnotetext{
${ }^{1}$ See Andreoni [5,6], Houser and Kurzban [7], Chaudhuri and Paichayontvijit [8], Ma, Sherstyuk, Dowling and Hill [9], Keser and Winden [10], Brandts and Schram [11], Offerman, Sonnemans and Schram [12] and Janssen and Ahn [13], among others.
} 
laboratory subjects, the framing of the game triggers a social norm coming from an indefinitely repeated game. The experience acquired in the game through trial and error adjustments changes behavior and may explain the decline in contributions.

Cooperation may survive in an infinitely repeated game, but even in a finite game, if there is a small probability that some subjects are not fully rational, rational subjects may react by contributing in the early periods and stop contributing toward the end of the game (see Kreps et al. [15]). Players may not want to trigger a break in cooperation when the others are contributing, but, of course, this argument is no longer valid as the end of the game approaches and, in particular, when lowering the contribution in the last period cannot trigger any retaliation. This argument can be extended. If players were aware that there would be no consequence from lowering contributions in the last period, and they thought others were likewise aware, they might also realize that lowering contributions in the previous to last period would not trigger any retaliation either. This unraveling would make the finite game equivalent to a one-shot game but it requires common knowledge of rationality. The question is therefore whether subjects do indeed solve the game by backward induction. There is some evidence that subjects find it difficult to apply this type of reasoning. Palacios and Volij [16] find that agents used to the backward induction arguments (chess players) applied it when playing the centipede game, while subjects who were more unfamiliar with it (students) did not use it to the same extent. Using backward induction seems to require some learning. The usual laboratory experiment repetitions of the PGG will not provide that learning as subjects face the end of the game only once. Johnson, Camerer, Sen and Rymon [17] have shown that subjects taught to use backward induction made equilibrium offers in an alternative offer bargaining game when playing with robots; however, when they played with untrained subjects they behaved differently, although closer to the equilibrium offers than prior to training. They conclude that both social preferences and a limited use of backward induction play a role in the discrepancy between the experimental outcome and the equilibrium prediction.

Problems with backward induction are not the only cognitive difficulties faced by players. Understanding the incentives in the one-shot game may also be an issue. Most papers have focused on this last type of limited cognition and on how learning through repetitions of the one-shot PGG mitigate its effects (see Anderson et al. [18], Andreoni [5,6], Brandts and Schram [11], Goeree et al. [19], Houser and Kurzban [7], Palfrey and Prisbey [20,21]). However, little attention has been paid to another source of cognitive limitation in PGG: the fact that subjects are not used to applying backward induction arguments in finite games, nor do they believe that other subjects will use this type of reasoning. To analyze this problem, we focus on the end-game effect ${ }^{2}$ in PGG and subjects' beliefs in this effect. ${ }^{3}$ Our work confirms the difficulties related to backward induction arguments in finite PGG; a majority of subjects do not predict any end-game effect at all, even when beliefs are elicited after playing the game.

After providing subjects experience with a 5-period repeated public good game and information on the resulting average contribution to the public good within their own group for each period (referred

\footnotetext{
${ }^{2}$ Several papers have dealt with the question of end-game effects. Gonzalez et al. [22] find that replacing a definite endpoint with an interval, whether commonly or privately known, does not change the timing of defection nor the average contribution levels.

${ }^{3}$ Several papers explore beliefs and elicitation mechanisms in PGG (see for instance Gätcher and Renner [23], Dufwenberg et al. [24], Iturbe-Ormaetxe et al. [25], Kovarik [26]).
} 
to as signals), we ask them to make predictions of contributions (referred to as guesses or ex-post beliefs) of all the groups that participate in the same 5-period game. We model ex-post beliefs as a linear combination of prior beliefs and the signals observed during the game. Our purpose is to determine how individuals process these two sources of information to establish their beliefs on the behavior of others. Our results suggest that the signal has a low weight in determining ex-post beliefs and, even though subjects experienced an end-game effect, this effect is absent from their ex-post beliefs.

The rest of the paper is organized as follows. Section 2 describes the game and Section 3 the experimental design and procedures. Section 4 presents our main results on average behavior and beliefs and in Section 5, we analyze individual behavior. Section 6 concludes.

\section{Description of the Game}

Players participate in a public good game in groups of $n$ players. The game is repeated $T$ times. At each stage of the game, player $i$ receives an endowment $w$ and has to decide how to distribute it between a contribution to a public good, $c_{i}$, and private consumption, $w-c_{i}$. The amount contributed by the $n$ members of a group is multiplied by $\beta, \beta<\mathrm{n}$, and equally shared by the $n$ members. Denoting $m=\beta / n, m<1$, the monetary payoff at each stage as a function of the contribution to the public good is: $\pi_{i}=w-c_{i}+m \sum_{i=1}^{n} c_{i}$.

If subjects maximize their monetary payoff, contributions in the subgame perfect equilibrium are zero. However, experimental research has shown that some subjects behave as conditional cooperators, that is, they are willing to contribute more to the public good game the more others contribute, while others behave as free riders. Assume some players find it optimal to contribute a proportion $x \leq 1$ of the average contribution $\bar{c}$ (conditional cooperators) and the rest are free riders $(x=0),{ }^{4}$ then for any $\mathrm{c}$ that players may initially hold as common belief on the average, contributions should collapse to zero since the belief $\bar{c}$ and the expected behavior of players (contribute at most $\bar{c}$ ) generate a lower estimated average which in turn lowers expected optimal contributions and the estimated average and so on. That is, if players unravel the game their expected average and the optimal contributions would be zero ${ }^{5}$ even if they have social preferences and conditionally cooperate.

Players may not have common beliefs on the average contribution (for example at the first period), but if they all use the observed average in the previous period as their belief on $\bar{c}$ the same argument applies. In the laboratory, convergence to zero contribution takes time so players do not unravel the game or they do not expect others to do so. The question is then how subjects form expectations about the contribution of others.

The previous argument suggests that the sustainability of cooperation may be more related to how players form beliefs regarding others' behavior than to social preferences so more research is needed

\footnotetext{
${ }^{4}$ For example, if players maximize (Bolton and Ockenfels [27]) $u_{i}\left(\pi_{i}, w-\frac{c_{i}}{\bar{c}_{i}}\right)=a_{i} \pi_{i}-\frac{b_{i}}{2}\left(\frac{c_{i}}{\bar{c}_{i}}-1\right)^{2}$, where $\bar{c}_{i}$ are beliefs on the average behavior, $a_{i} \geq 0, b_{i} \geq 0$, optimal contributions are $c_{i}=\bar{c}_{i}\left[1-\frac{a_{i}}{b_{i}}(1-m)\right] \leq \bar{c}_{i}$ or 0 if $b_{i}=0$.
}

See also Fischbacher, Gächter and Fehr [28] for experimental evidence.

${ }^{5}$ This is similar to a guessing game. 
on how these expectations are formed. Players may use their priors or the previous period average as an estimate of $\bar{c}$ and they may also take into account that contributions will be declining over time.

We model belief formation in repeated interactions as follows. At the first stage of the game, subjects maximize their preferences using priors as the estimate of the average behavior and after playing the game, they observe the average contribution and use it as a signal $s_{i}$ for the average behavior for next period. Players update beliefs using all the information available, priors and the signal, and generate posterior beliefs $g_{i}$ that will be used as the estimate of average behavior at the next stage of the game ${ }^{6}$ :

$$
g_{i}=(1-\alpha) p_{i}+\alpha s_{i}
$$

Our empirical research is focused on how players update their beliefs after observing other players' contribution. We also check whether subjects expect an end-game effect.

\section{Experimental Design}

The experiment was carried out in a single session at Universidad de Granada on 31 May, 2007. Participants were first-year undergraduate students in Economics. The total number of participants was 48 divided into 12 groups. Students were told that they would perform several tasks (See the Instructions in the Appendix 2).

For the first task, subjects played a linear public good game (PGG) in each group for five periods. Subjects were informed that they would be playing with the same partners for the five periods. In each period, the subjects were given an endowment of 100 2-eurocent coins. They were asked to make a decision on how much to allocate to a private account and how much to allocate to a public account. Contributions were expressed in number of coins; thus, they were integer numbers between 0 and 100 , $c_{i t} \in[0,100]$. Participants were informed that they could keep any money allocated to the private account for themselves, and this would be independently of the other subjects' actions, while all the money allocated to the public account (the sum of the money allocated by the four members of the group) would be multiplied by 1.5 and then divided equally among the four members. Each participant earned the sum of payoffs obtained in the five periods.

After each period, each subject received feedback privately on his own payoff, $\pi_{i t}$. Prior to the new period starting, they were given a new endowment of 100 2-eurocent coins. Figure 1 summarizes the timing of the experiment.

\footnotetext{
${ }^{6}$ This expression for the updating of beliefs is justified as follows: If the individual has $k$ information sources on the value of the average contribution $c: x_{1}, \ldots, x_{k}$ such that $x_{i} \approx N\left(c, \sigma_{i}^{2}\right)$ the quality of the $i$ th information source is given by its precision, $\psi_{i}=1 / \sigma_{i}^{2}$. Then, the conditional expectation of $c$ satisfies: $E\left[c / x_{i}, \ldots, x_{k}\right]=\sum_{i=1}^{k} \psi_{i} x_{i} / \sum_{i=1}^{k} \psi_{i}$, that is the weighted average of the different information sources. Thus, a rational player would weight the priors and the signal according to the relative quality of each information source $\alpha_{i}=\psi_{i} / \psi_{1}+\psi_{2}$
} 
Figure 1. Timing of the experiment. Task 1, 5 periods of contributions with feedback; Task 2, belief elicitation.

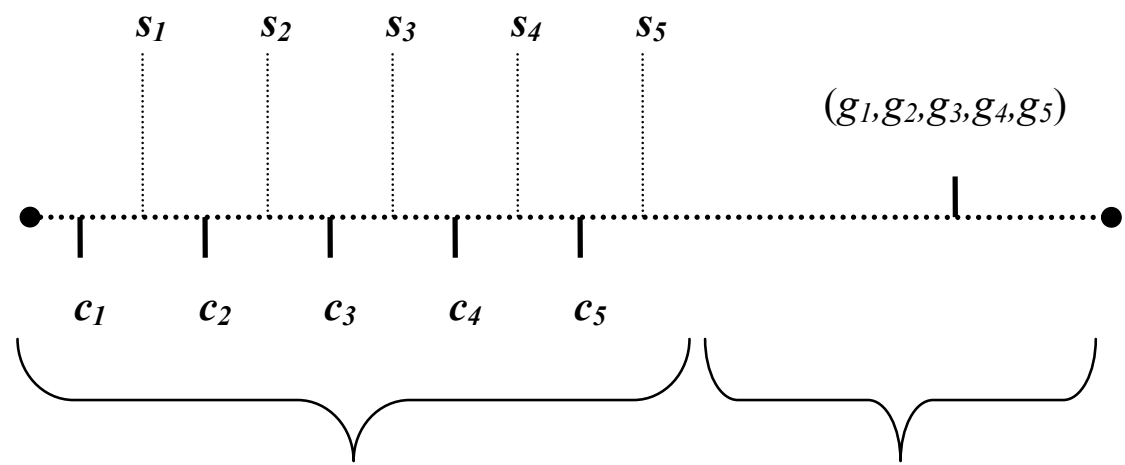

Task 1

Task 2

After making decisions on contributions to the public account for 5 periods, and getting feedback on their payoffs, subjects started Task 2.

In Task 2, they were asked about their beliefs regarding the average contributions to the public account (in number of coins) of the 48 participants and for each of the five periods $\left(g_{i t}\right)$. We used an incentive scheme according to their errors, $\varepsilon_{i t}=\operatorname{int} c_{i}-g_{i t}$ (being int $c_{i}$ the integer of the observed average and $t=1, \ldots, 5)$. More precisely, ${ }^{7}$

- If $\left|\varepsilon_{i t}\right|>10$ participant $i$ did not receive anything;

- If $5<\left|\varepsilon_{i t}\right| \leq 10$ participant $i$ received 1 euro;

- If $0<\left|\varepsilon_{i t}\right| \leq 5$ participant $i$ received 2 euros;

- $\quad$ Finally, if $\varepsilon_{i t}=0$ participant $i$ would receive 20 euros.

Participants were told that only one of the periods chosen at random would determine their payoff for Task 2.

We did not perform a belief elicitation step before Task 1 to avoid any possible effects on contributions. ${ }^{8}$ Since our main interest was to determine how priors are affected by the experience of playing the game and whether the priors or the posterior beliefs incorporate any end-game effect, we chose a design with a low number of periods. This design makes the end-effect very important in the game experience and increases the chances of observing it in the forecasts. Subjects also had enough time to think about what they would do; participants were given a few minutes after each decision,

\footnotetext{
${ }^{7}$ Alternative reward functions include quadratic and linear scoring rules and other procedures that correct for risk attitudes (Karni [29]). The interval schedule was used for the simplicity of explaining the rule. It is similar to scoring rules that provide a positive reward for an exact prediction and zero otherwise (Charness and Dufwenberg [30] and Dufwenberg, Gächter and Hennig-Schmidt [24], among others, have used these rules). These scoring rules elicit the mode of the subjective probability distribution for a risk neutral subject (see Andersen, Fountain, Harrison and Rutström [31]). Since we are eliciting forecasts on the average contribution of subjects, it is likely that subjective distributions are unimodal and symmetric.

${ }^{8}$ The evidence on whether belief elicitation may affect contribution is mixed. See for example Gächter and Renner [23].
} 
then the feedback about payoffs was received and then the following period would start. In Task 2, subjects had the feedback received in the five periods at their disposal, so that any possible differences in recall between subjects could not introduce any noise in the results. Note that subjects do not observe contributions but may infer the level of group contributions very easily as $\frac{\text { feedback } 4}{1.5}$. Even if they did not explicitly calculate contributions, it should be noted that our purpose was not to determine whether subjects are accurate in their predictions, but rather only if they could predict the end-game effect. If they observed a decline in profits from the public account, this could only come from a decline in contributions. We did not provide data on contributions to avoid the implicit suggestion that they should use the average of the group in their predictions. This design allows us to measure the relative importance of priors and the subjects' experience in Task 1 (group signals) in the subjects' forecasts in Task 2. The complete experiment lasted about an hour and subjects earned, on average, 13.47 euros.

\section{Average Behavior}

We first compared actions and elicited beliefs. We checked whether subjects, who had played the PGG for five periods and had received feedback about their own payoff after each period, could accurately predict the mean contribution of the population and to what extent they could predict any end-game effects. Since forecasts were elicited in Task 2, they will be called posterior beliefs.

Figure 2 shows both the average posterior beliefs (over the whole population) and average actions in each period in the 4-player public good game. ${ }^{9}$

The average of contributions in the first three periods is 35.3 , which is not very different from the average forecasts, 33.4. In the last two periods, however, there is a discrepancy between average contributions (18.1) and beliefs (29.3), suggesting that the end-game effect observed in contributions in the last two periods was not predicted in Task 2.

Figure 2. Contributions (task 1) and beliefs (task 2).

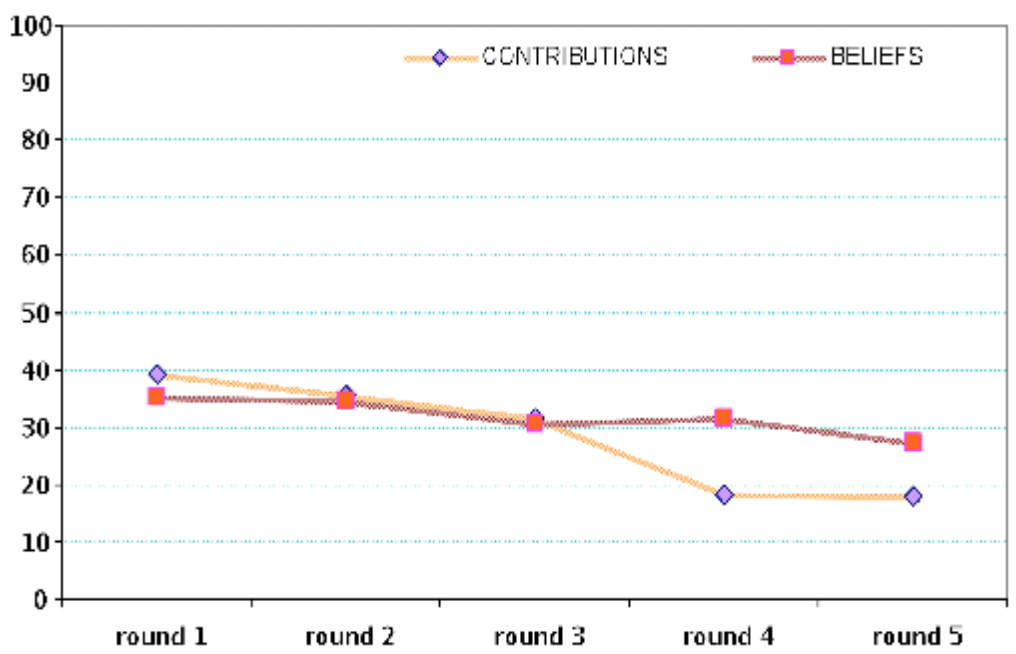

\footnotetext{
${ }^{9}$ The descriptive statistics of contributions and beliefs can be found in the appendix 1 . There is large heterogeneity among subjects both in contributions and beliefs.
} 
Observe that whereas subjects changed their behavior in period 4, this change was not incorporated into posterior beliefs for that period and, despite a small decrease in guesses at the last period (weakly significant), subjects overstated the value of the participants' contribution at the end of the game.

To explore differences between actions and beliefs in period $t$, we define the error or discrepancy between them as $e_{i t}, e_{i t}=c_{t}-g_{i t}(t=1,2, \ldots, 5)$. Table 1 summarizes these discrepancies.

Table 1. Belief accuracy $(n=48)$.

\begin{tabular}{cccc}
\hline errors & mean & median & st. dev. \\
\hline $\mathrm{e}_{1}$ & 4.02 & 4.01 & 19.68 \\
$\mathrm{e}_{2}$ & 0.97 & 5.39 & 18.29 \\
$\mathrm{e}_{3}$ & 0.81 & 4.39 & 17.29 \\
$\mathrm{e}_{4}$ & -13.04 & -10.63 & 18.17 \\
$\mathrm{e}_{5}$ & -9.37 & -5.63 & 17.01 \\
\hline
\end{tabular}

Recall that positive values indicate low guesses. The mean difference between actions and beliefs was relatively small for the first three periods. However, the average difference increased in periods 4 and 5 and became negative. Subjects did not predict end-game effects, and contributions and guesses diverged. We checked whether $c_{t}$ and $g_{t}$ are drawn from the same population using paired non-parametric test. The Wilcoxon test compares $c_{t}$ and $g_{t}$ for each round. $Z_{1}=-0.50(p$-value $=0.61)$; $Z_{2}=-0.11(0.91) ; Z_{3}=-0.28(0.77) ; Z_{4}=-3.83(0.00)$ and $Z_{5}=-2.96(0.00)$. The sign test yields similar results: $S_{1}=0.00$ ( $p$-value $\left.=1.00\right) ; S_{2}=0.00(1.00) ; S_{3}=-0.43(0.66) ; S_{4}=-3.89(0.00)$ and $S_{5}=-3.20(0.00)$.

Hence, subjects' average beliefs matched average actions fairly well for the first three rounds (despite the high variance of belief accuracy) but failed to do so in $T$ and $T-1$. In period 4, when the end-game effect was first observed, and in period 5, the differences between the two are statistically significant. Therefore, subjects did not incorporate the decline in contributions to their beliefs, although the small decline in guesses at the last period is weakly significant (see Figure 2 and Table 2).

Table 2. Evolution of $c_{t}$ and $g_{t}(n=48)$. Non-parametric test for 2-paired samples.

Wilcoxon and Sign tests. $\mathrm{H}_{0}$ : data are drawn from the same sample, Significant coefficients are reported in bold; $\mathrm{p}-\mathrm{v}=\mathrm{p}$-value.

\begin{tabular}{|c|c|c|c|c|c|c|c|c|c|}
\hline & \multicolumn{2}{|c|}{ Wilcoxon } & \multicolumn{2}{|c|}{ Sign } & & \multicolumn{2}{|c|}{ Wilcoxon } & \multicolumn{2}{|c|}{ Sign } \\
\hline$\Delta c$ & $\mathrm{Z}$ & $\mathrm{p}-\mathrm{v}$ & $\mathrm{S}$ & $\mathrm{p}-\mathrm{V}$ & $\Delta \mathrm{g}$ & $\mathrm{Z}$ & $\mathrm{p}-\mathrm{V}$ & $S$ & $\mathrm{p}-\mathrm{v}$ \\
\hline$c_{1}, c_{2}$ & -0.02 & 0.98 & 0.00 & 1.00 & $\mathrm{~g}_{1}, \mathrm{~g}_{2}$ & -0.25 & 0.80 & -0.45 & 0.65 \\
\hline$c_{2}, c_{3}$ & -0.19 & 0.84 & 0.00 & 1.00 & $\mathrm{~g}_{2}, \mathrm{~g}_{3}$ & 1.30 & 0.19 & -1.22 & 0.22 \\
\hline$c_{3}, c_{4}$ & -2.34 & 0.01 & -1.83 & 0.06 & $\mathrm{~g}_{3}, \mathrm{~g}_{4}$ & -0.15 & 0.88 & 0.00 & 1.00 \\
\hline $\mathrm{c}_{4}, \mathrm{c}_{5}$ & -0.52 & 0.60 & -0.50 & 0.61 & $\mathrm{~g}_{4}, \mathrm{~g}_{5}$ & -1.69 & 0.09 & -1.73 & 0.08 \\
\hline
\end{tabular}

Regarding average behavior, we may conclude that:

Result 1(a) There was an end-game effect at period $T-1$.

1(b) On average, players did not incorporate the strong decline in contributions to their posteriors beliefs. 
Result 1 refers to average behavior. However, different types of players may follow different patterns. ${ }^{10}$ We will address this issue in the next section.

\section{Individual Results}

Figure 2 shows the extent of the end-game phenomenon in aggregate beliefs and contributions. We will now analyze individual behavior and beliefs to explore the question in greater depth. Figure 3 shows the histogram for the discrepancies between contributions and guesses for each period. Non-negative errors are represented in the shaded area. Individuals within the unshaded area overestimated mean contributions, that is, they were optimistic.

Figure 3. Histograms for discrepancies between contributions and guesses. Non-negative errors are represented in the shaded area. The unshaded area indicates overestimation of mean contributions.

\section{Period 1}

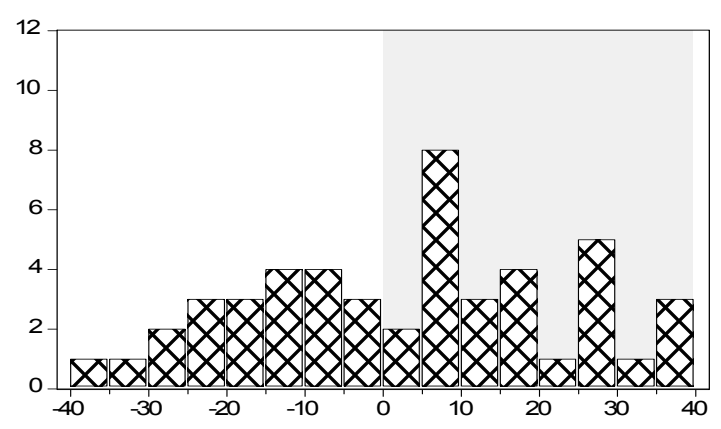

Period 3

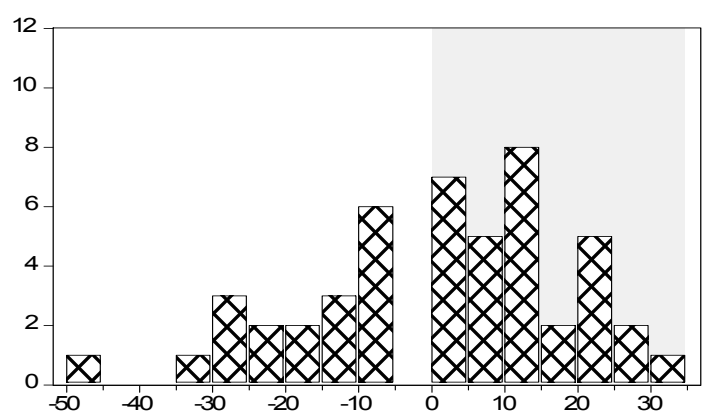

Period 2

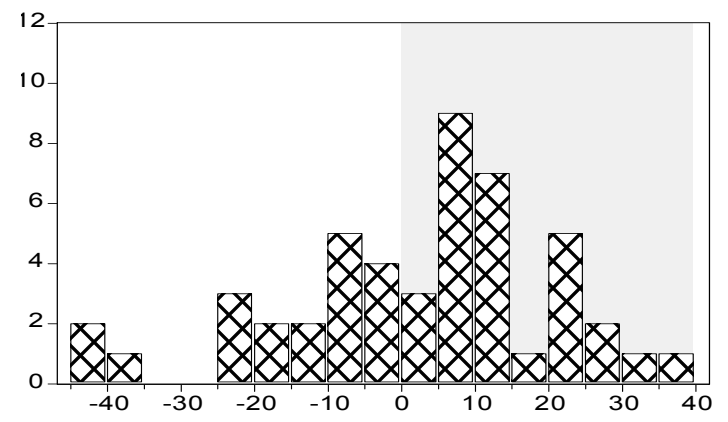

Period 4

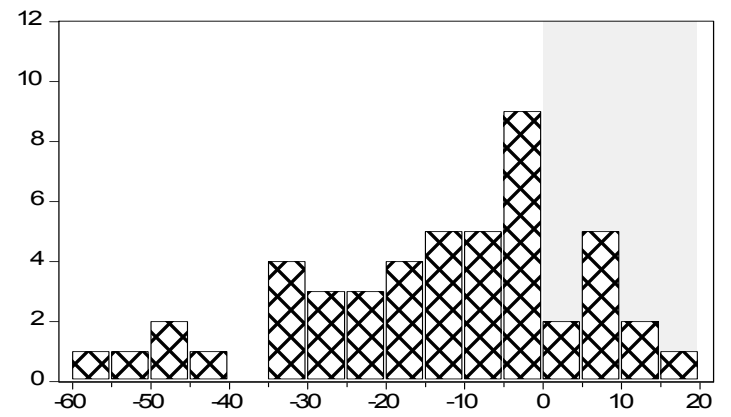

Period 5

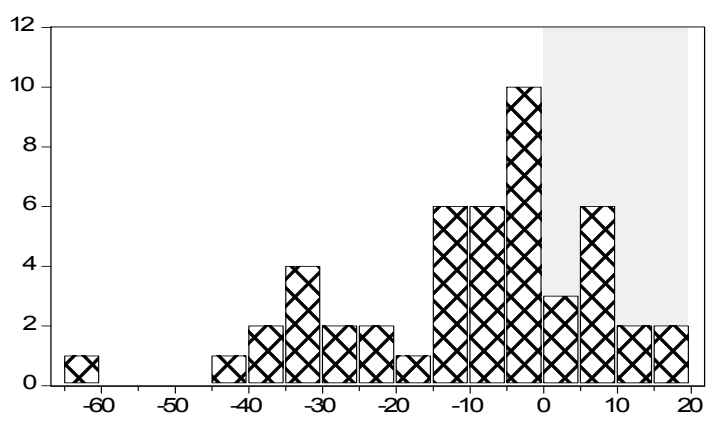

\footnotetext{
${ }^{10}$ Previous work on PGG has shown evidence of subjects' heterogeneity. For instance, Fischbacher et al. [28] and Chaudhuri \& Paichayontvijit [8] found that some players are conditional cooperators and others are free-riders.
} 
The percentage of subjects over- and underestimating contributions remained balanced for periods 1 to 3 . However, the percentage of subjects with optimistic predictions increased notably after round 4 and broke the balance.

Figure 2 shows that there was an end-game effect at period 4, but the mean predictions did not incorporate it. We may conclude from Figure 3 that not only the mean but a relevant percentage of the individuals did not predict this decline.

To improve our understanding of these phenomena we will now focus on the period when they lowered contributions and the period when they believed the end game phenomenon would occur. We define a decrease in contributions (in rows) as lowering the contribution to a value (i) lower than $2 / 3$ of the previous value and (ii) lower than $2 / 3$ of the average of the own contribution in previous periods, provided the decrease is maintained up to the last period. ${ }^{11}$ Identical criterion is used for guesses.

- contributions: $25 \%$ (12 out of 48 ) of subjects decreased their contribution in period $4,12.5 \%$ defected at period 5, but a high percentage of subjects $(23 \%)$ did not decrease their contribution as the end of the game approached.

- beliefs: 25 out of 48 subjects (52\%) did not predict any end-game effect; 10 subjects (21\%) believed that the end-game effect would occur at the last period and only one made the right prediction (decline at period 4).

This means that $73 \%$ (35 out 48 ) of the players either predicted the decrease in contributions later than the period in which the decrease took place or they did not predict it at all. This is remarkable since at the time of the prediction they had already seen the outcome of the five periods of the contribution game in their own group of four subjects (although the prediction referred to the average of all participants). Subjects had the opportunity to update their beliefs with the observed behavior in their group, in case they had not predicted ex ante the end-game effect.

Result (2) Half of the subjects did not incorporate the observed end-game effects into their posterior beliefs.

We will now try to rationalize this result by looking at how posterior beliefs are formed. Beliefs were elicited after playing the PGG so that they must be a combination of ex-ante beliefs (priors) and the signals observed throughout the game. Subjects did not observe other players contributions, but they did observe the part of the payoff that comes from their group contributions to the public account. ${ }^{12}$ We define this value as the signal ${ }^{13}$ observed by individual $i$ in group $z$ at each period $t$ :

\footnotetext{
${ }^{11}$ The actual decrease in the average contribution in period 4 was from $(39.3 ; 35.4$; and 31.4$)$ to $(18.4 ; 17.9)$ which fulfills this criterion. Small changes in the threshold do not change results (choosing 0.6 or 0.7 leaves results almost unchanged).

${ }^{12}$ Concerning accuracy when beliefs are elicited period by period or at the end of the game, the average absolute estimation error in Croson [32], Figure 2) in the first five periods has an average of around 13, lower than our prediction error, 15.4, but the difference is not large. The problem with eliciting beliefs period by period is that it may affect contributions: Croson [32] finds a substantial decrease in contributions when beliefs are elicited period by period.

${ }^{13}$ An alternative signal could be the subjects' payoffs (private + public account). We also used this variable as the signal (see footnote 16).
} 


$$
S_{i t}=\frac{1.5 \sum_{i \in t} c_{i t}}{4}
$$

We model ex-post beliefs as a weighted average of prior beliefs and the signal observed in the game for each individual $i$; the weights represent the relative importance of each source of information:

$$
g_{i t}=(1-\alpha) p_{i t}+\alpha s_{i t}
$$

where prior beliefs of individual $i, p_{i t}$, might vary across periods.

As we observe $s_{i t}$ and $g_{i t}$ we can obtain an estimation of $\alpha$. The assumption is that the weight given to the signal and that given to the priors are the same for all individuals. We estimate the following panel regression with fixed effects:

$$
g_{i t}=\underbrace{\left[\gamma_{0}+\gamma_{i}+\sum_{t=2}^{5} \beta_{t} d_{t}\right]}_{(1-\alpha) p_{i t}}+\alpha s_{i t}+u_{i t}
$$

where $\gamma_{0}$ is the constant, $\gamma_{i}$ are individual fixed effects (reflecting subjects' heterogeneity), and $d_{t}$ are period dummies allowing priors to be different across periods; the estimated parameters $\hat{\beta}_{t}$ will be an indication of how individuals predict the end-game effect (if they do, parameters $\hat{\beta}_{4}$ and $\hat{\beta}_{5}$ will be negative and significant), and $u_{i t}$ is the error term.

Table 3 shows the regression results. The period dummies are not significant. The implication is that when we separate the effect of the priors and that of the signal, priors are not time dependent, i.e., on average subjects did not predict ex ante a decline in contributions over time.

Eliminating the time dummies from the regression yields the coefficients shown on the second column of Table 3, regression (2). The estimated weight of the signal, $\hat{\alpha}$, is $14 \%$ and the weight of the priors, $1-\hat{\alpha}$, is six times larger. ${ }^{14}$

We have also added two dummies to check if different types of players have a different behavior concerning beliefs regarding the endgame. Surprisingly, the beliefs of subjects who decreased their contributions at the end of the game (endgamer) do not follow a different pattern. The dummy for free riders (subjects who gave less than 5 in at least three periods) is not significant either.

In regression (2) we may obtain a measure of each individual prior beliefs weighted by $(1-\hat{\alpha})$ through the predicted constant and fixed effects: $\hat{\gamma}_{0}+\hat{\gamma}_{i}$ (see Equation (1)). We calculate the main statistics for the (predicted) prior beliefs: the mean (std. dev.) is 25.97 (14.47) and the $\max (\min )$ is $69.3(-0.8) .{ }^{15}$ Therefore, we observe a large heterogeneity in priors across subjects.

\footnotetext{
${ }^{14}$ If we normalize signals to reflect average contribution of the group: $\frac{\sum_{i} c_{i t}}{4}$, the estimated coefficient of the normalized signal is 0.21 .

${ }^{15}$ The unweighted values are 30.20 and 80.58 , respectively.
} 
Table 3. Regression results. Beliefs, $g_{i t}$.

\begin{tabular}{|c|c|c|c|c|}
\hline beliefs $\left(g_{i t}\right)$ & (1) & $(2)$ & (3) & (4) \\
\hline $\operatorname{signal}\left(s_{i t}\right)$ & $0.11 * * *(0.04)$ & $0.14 * * *(0.03)$ & $0.12 * * *(0.04)$ & $0.12 * * *(0.04)$ \\
\hline constant & $28.80 * * *(3.11)$ & $25.95 * * *(1.68)$ & $29.28 * * *(4.01)$ & $31.09 * * *(5.38)$ \\
\hline $\mathrm{d}_{2}$ & $-0.21(2.38)$ & & $-0.16(2.38)$ & $-0.15(2.38)$ \\
\hline $\mathrm{d}_{3}$ & $-3.38(2.42)$ & & $-3.27(2.42)$ & $-3.25(2.42)$ \\
\hline $\mathrm{d}_{4}$ & $-0.41(2.74)$ & & $-0.11(2.72)$ & $-0.06(2.72)$ \\
\hline $\mathrm{d}_{5}$ & $-4.49(2.76)$ & & $-4.18(2.74)$ & $-4.14(2.73)$ \\
\hline Free-rider & & & $-2.94(4.53)$ & \\
\hline End-gamer & & & & $-3.83(5.06)$ \\
\hline$n=240$ & $\begin{array}{c}F=4.15 \\
p \text {-value }=0.00\end{array}$ & $\begin{array}{c}F=14.98 \\
p \text {-value }=0.00\end{array}$ & $\begin{array}{c}F=23.36 \\
p \text {-value }=0.00\end{array}$ & $\begin{array}{c}F=23.46 \\
p \text {-value }=0.00\end{array}$ \\
\hline
\end{tabular}

Summing up our results in this section,

Result 3(a) Priors are constant across periods, that is, subjects did not predict ex ante any end-game effects. There is a large heterogeneity in priors.

3(b) In the formation of posterior beliefs, the weight given to the signal $(-\hat{\alpha})$ is relatively low: $10 \%-15 \%$. Priors are given a much larger weight.

To check the robustness of this result, we considered two alternative signals that the subject could use to update his priors: own contributions or the payoff he received in each period. However, these signals turned out not to be significant. ${ }^{16}$ In sum, subjects do not use their own contribution or the payoff as signals to form their posterior beliefs, but the average contribution of their group (the relevant signal is 1.5 times the average contribution of the group, the payoff from the public good).

There were two groups which did not experience any endgame effect. In terms of beliefs, these two groups did not behave differently from the others and therefore having experienced the endgame effect does not seem to affect beliefs. Looking at the endgame effect in beliefs group by group, only in one of the groups the average guess went below the $2 / 3$ rule at the end; there was no endgame effect in guesses in the other 11 groups.

The low weight given to the signal is consistent with the fact that although individuals experienced an end-game effect, they did not guess it after the game. Other papers have found evidence in the same direction: subjects barely update their beliefs (see Kovarik [26]). Given the low weight given to signals, we should not expect large learning effects from repetitions of a finite PGG. ${ }^{17}$

\footnotetext{
${ }^{16}$ Using the individual payoffs as signals yields a coefficient 0.02 (p-value $\left.=0.61\right)$; for individual contributions the coefficient is 0.04 ( $p$-value $=0.25$ ). Adding subjects' contributions or payoffs in regressions (1) and (2) does not change results substantively in terms of the estimated coefficient of $s_{i t}$.

${ }^{17}$ This is also consistent with the low speed of learning observed in the centipede game (see Palacios and Volij [16]).
} 


\section{Conclusions}

In the experimental literature on PGG, repetition of the one-shot game has been shown to decrease contributions. Repetition introduces learning effects, strategic considerations and the possibility of punishment for the unfair behavior of others ${ }^{18}$ that could be related to the decrease in contributions.

We contribute to this literature on experimental public good games with the idea that the subjects' abilities to unravel the game (or their beliefs on the ability of others to do so) may be an important factor behind the experimental results. We performed this analysis by asking subjects about their beliefs regarding average contributions for each period. The belief elicitation was conducted after the PGG to avoid any interference with contributions.

Our regression analysis allowed us to measure the relative importance of priors and signals on subjects' belief formation. Our main results are that priors are constant for all periods and they have a significant weight compared to the signals observed throughout the game.

Our analysis suggests that, prior to playing the game, subjects do not expect backward induction, not even in the last few periods, and their updating using the observed signals is slow. Therefore, the posteriors beliefs do not incorporate the end-game effect.

Previous papers have studied the reasons behind contributions: conditional cooperation (Fischbacher and Gächter [33]), kindness, altruism or warm-glow vs. errors or confusion (see Croson [32-34]; Andreoni [6]; Houser and Kurzban [7] among others). Our paper focuses on a different kind of confusion: people are not able to predict end-game effects. However, this confusion is not inconsistent with individuals endowed with other-regarding preferences and, more precisely, with subjects who consider that other players could have social preferences. Moreover, we have shown that the rate of decline in contributions and the sustainability of cooperation may be related to how players form expectations.

\section{Acknowledgments}

We gratefully acknowledge comments and suggestions from three anonymous referees. We also thank comments from Jordi Brandts, Werner Guth, Vitoria Levatti, Maite Martínez-Granado and participants at the Max Planck Institute Jena seminar and Alhambra Experimental Workshop. María Paz Espinosa acknowledges financial aid from MICINN (ECO2009-09120) and Gobierno Vasco, DEUI (IT-313-07); Pablo Brañas-Garza from MICINN (ECO2010-17049) and Junta de Andalucía (P07-SEJ-2547).

\section{References}

1. Davis, D.; Holt, C.A. Experimental Economics; Princeton University Press: Princeton, NJ, USA, 1993.

2. Isaac, M.R.; McCue, K.F.; Plott, C.R. Public goods provision in an experimental environment. J. Public Econ. 1985, 26, 51-74.

3. Kim, O.; Walker, M. The free rider problem: Experimental evidence. Public Choice 1984, 43, 3-24.

\footnotetext{
${ }^{18}$ See Andreoni [6] and Houser and Kurzban [7].
} 
4. Ledyard, J.O. Public Good: A Survey of experimental research. In The Handbook of Experimental Economics; Kagel, J.H., Roth, A.E., Eds.; Princeton University Press: Princeton, NJ, USA, 1995.

5. Andreoni, J. Why free ride? Strategies and learning in public goods experiments. J. Public Econ. 1988, 37, 291-304.

6. Andreoni, J. Cooperation in public-goods experiments: Kindness or confusion? Am. Econ. Rev. 1995, 85, 891-904.

7. Houser, D.; Kurzban, R. Revisiting kindness and confusion in public goods experiments. Am. Econ. Rev. 2002, 92, 1062-1069.

8. Chaudhuri, A.; Paichayontvijit, T. Conditional cooperation and voluntary contributions to a public good. Econ. Bull. 2006, 3, 1-14.

9. Ma, L.; Sherstyuk, K.; Dowling, M.; Hill, O. Altruism and voluntary provision of public goods. Econ. Bull. 2002, 3, 1-8.

10. Keser, C.; van Winden, F. Conditional cooperation and voluntary contributions to public goods. Scand. J. Econ. 2000, 102, 23-39.

11. Brandts, J.; Schram, A. Cooperation or noise in public goods experiments: Applying the contribution function approach. J. Public Econ. 2001, 79, 399-427.

12. Offerman, T.; Sonnemans, J.; Arthur S. Value orientations, expectations and voluntary contributions in public goods. Econ. J. 1996, 106, 817-845.

13. Janssen, M.A.; Ahn, T.K. Learning, signalling and social preferences in public-good games. Ecol. Soc. 2006, 11, 1-23.

14. Binmore, K. Why do people cooperate. Polit. Philos Econ. 2006, 5, 81-96.

15. Kreps, D.; Milgrom, P.; Roberts R.; Wilson, R. Rational cooperation in the finitely repeated prisoners' dilemma. J. Econ. Theory 1982, 27, 245-252.

16. Palacios, I.; Volij, O. Field centipedes. Am. Econ. Rev. 2009, 99, 1619-1635.

17. Johnson, E.; Camerer, C.; Sen, S.; Rymon, T. Detecting failures of backward induction. J. Econ. Theory 2002, 104, 6-47.

18. Anderson, S.P.; Goeree, J.; Holt, C.A. A theoretical analysis of altruism and decision error in public goods games. J. Public Econ. 1998, 70, 297-323.

19. Goeree, J.; Holt, C.A.; Laury, S. Private costs and public benefits: Unraveling the effects of altruism and noisy behavior. J. Public Econ. 2002, 83, 257-278.

20. Palfrey, T.R.; Prisbey, J.E. Altruism, reputation, and noise in linear public goods experiments. J. Public Econ. 1996, 61, 409-427.

21. Palfrey, T.R.; Prisbey, J.E. Anomalous behavior in linear public goods experiments: How much and why? Am. Econ. Rev. 1997, 87, 829-846.

22. González, L.G.; Guth, W.; Levati, M.V. When does the game end? Public goods experiments with non-definite and non-commonly known time horizons. Econ. Lett. 2005, 88, 221-226.

23. Gächter, S.; Renner, E. The effects of (incentivized) belief elicitation in public goods experiments. Exp. Econ. 2010, 13, 364-378.

24. Dufwenberg, M.; Gachter, S.; Hennig-Schmidt, H. The framing of games and the psychology of play. Games Econ. Behav. 2011, 73, 459-478.

25. Iturbe-Ormaetxe, I.; Ponti, G.; Tomás, J.; Ubeda, L. Is prevention better than cure? Framing effects in public good provision. Games Econ. Behav. 2011, 72, 439-447. 
26. Kovarik, J. Belief Formation and Evolution in Public Good Games; Universidad de Alicante: San Vicente del Raspeig, Spain, 2007; unpublished work.

27. Bolton, G.E.; Ockenfels, A. ERC: A theory of equity, reciprocity and competition. Am. Econ. Rev. 2000, 90, 166-193.

28. Fischbacher, U.; Gachter, S.; Fehr, E. Are people conditionally cooperative? Evidence from a public goods experiment. Econ. Lett. 2001, 71, 397-404.

29. Karni, E. A mechanism for eliciting probabilities. Econometrica 2009, 77, 603-606.

30. Charness, G.; Dufwenberg, M. Promises and partnership. Econometrica 2006, 74, 1579-1601.

31. Andersen, S.; Fountain, J.; Harrison, G.W.; Ruström, E. Inferring beliefs as subjectively imprecise probabilities. Theory Decis. 2011, doi:10.1007/s11238-011-9276-1

32. Croson, R. Thinking like a game theorist: Factors affecting the frequency of equilibrium play. J. Econ. Behav. Organ. 2000, 41, 299-314.

33. Fischbacher, U.; Gächter S. Social preferences, beliefs, and the dynamics of free riding in public goods experiments. Am. Econ. Rev. 2010, 100, 541-556.

34. Croson, R. Theories of commitment, altruism and reciprocity: Evidence from linear public goods games. Econ. Inq. 2007, 45, 199-216.

35. Gachter, S.; Renner, E. The effects of (incentivized) belief elicitation in public goods experiments. Exp. Econ. 2010, 13, 364-377.

\section{Appendix}

Appendix 1. Descriptive statistics, contributions and beliefs.

\begin{tabular}{ccccc}
\hline \multicolumn{5}{c}{ Guesses: Basic statistics } \\
\hline \multicolumn{7}{c}{ mean } & standard dev. & min & max \\
\hline$t=1$ & 35.27 & 19.98 & 0 & 78 \\
$t=2$ & 34.42 & 18.23 & 0 & 80 \\
$t=3$ & 30.58 & 17.90 & 0 & 78 \\
$t=4$ & 31.42 & 18.17 & 3 & 78 \\
$t=5$ & 27.25 & 17.02 & 0 & 78 \\
\hline \multicolumn{5}{c}{ Contributions: Basic statistics } \\
\hline $\mathrm{t}=1$ & mean & standard dev. & min & max \\
$\mathrm{t}=2$ & 39.29 & 36.53 & 0 & 100 \\
$\mathrm{t}=3$ & 35.40 & 33.78 & 0 & 100 \\
$\mathrm{t}=4$ & 18.38 & 33.83 & 0 & 100 \\
$\mathrm{t}=5$ & 17.87 & 24.07 & 0 & 100 \\
\hline
\end{tabular}


Appendix 2. Instructions.

\section{WELCOME TO THIS EXPERIMENT}

Granada, May 31, 2007

In this experiment you will perform several tasks.

\section{TASK 1}

Task 1 consists of 5 independent rounds. You will be a member of the same 4-member group during the 5 rounds.

At the beginning of each period, each participant receives an amount of 100 coins of 2 euro cents.

Your only decision is how much you want to keep for yourself (Private Account) and how much to assign to a Public Account in your group. Any amount not assigned to the Public Account goes to your Private Account.

The amount you will get from the Private Account is equal to the amount of money you assigned to it and this is independent of the decisions of the other participants.

The amount you will get from the Public Account in your group depends on the sum of the amounts of money assigned to it by all members of your group (that is, the amount you have decided to assign to it plus the amounts that the other 3 members of your group have decided to assign to the Public Account). This sum is multiplied by 1.5 and then divided in 4 parts. Each of these four equal parts goes to a member of the group.

Summing up, the amount of money you win in each round is calculated as follows:

The amount you win $=$ Amount from your Private Account + Amount from the Public Account in your group

Before we start Task 1, remember that you have to decide how to distribute the money between your PRIVATE Account and the PUBLIC Account of your group.

You will play 5 rounds. Remember that in each round your will have 100 coins of two euro cents (that is, 2 Euros).

\section{----- pagebreak -----}

We will now start Task 1:

- Write in the first row of the form provided (Round 1) how much money you put into the PUBLIC Account.

- The amount you write must be between 0 and 100 .

- After you make your decision (you will have to wait a few minutes) you will be informed of the amount of money you have won in the round (we will fill out the cell on the right, "The amount you win"). 
Round 1

\begin{tabular}{|l|l|l|}
\hline & Contribution to the PUBLIC Account & The amount you win \\
\hline Round 1 & XXXXXX & (we fill out this cell) \\
\hline Round 2 & & \\
\hline Round 3 & & \\
\hline Round 4 & & \\
\hline Round 5 & & \\
\hline
\end{tabular}

\section{----- pagebreak -----}

We will now start a second round. You have 100 coins to assign to the Public Account or to the Private Account.

Please write in the second row of the form provided (Round 2) the amount you want to put into the Public Account in this second round.

As before, after a few minutes we will inform you of the amount of money you have won in this second round.

Round 2

\begin{tabular}{|l|l|l|}
\hline & Contribution to the PUBLIC Account & The amount you win \\
\hline Round 1 & & \\
\hline Round 2 & XXXXXX & (we fill out this cell) \\
\hline Round 3 & & \\
\hline Round 4 & & \\
\hline Round 5 & & \\
\hline
\end{tabular}

----- pagebreak -----

We will now start a third round. You have 100 coins to assign to the Public Account or ....... 
Round 3

\begin{tabular}{|l|l|l|}
\hline & Contribution to the PUBLIC Account & The amount you win \\
\hline Round 1 & & \\
\hline Round 2 & & \\
\hline Round 3 & XXXXXX & (we fill out this cell) \\
\hline Round 4 & & \\
\hline Round 5 & & \\
\hline
\end{tabular}

----- pagebreak -----

We will now start a fourth round. You have 100 coins to assign to the Public Account or .....

Round 4

\begin{tabular}{|l|l|l|}
\hline & Contribution to the PUBLIC Account & The amount you win \\
\hline Round 1 & & \\
\hline Round 2 & & \\
\hline Round 3 & & \\
\hline Round 4 & XXXXXX & (we fill out this cell) \\
\hline Round 5 & & \\
\hline
\end{tabular}

----- pagebreak -----

Now we start a fifth round. You have 100 coins to assign to the Public Account or .....

Round 5

\begin{tabular}{|l|l|l|}
\hline & Contribution to the PUBLIC Account & The amount you win \\
\hline Round 1 & & \\
\hline Round 2 & & \\
\hline Round 3 & & \\
\hline Round 4 & & \\
\hline Round 5 & XXXXXX & (we fill out this cell) \\
\hline
\end{tabular}

The five rounds are over.

All the money you have won IS YOURS. We will now start Task 2 and you may earn more money. 


\section{TASK 2}

Your task is to find out the average contribution to the Public Account of ALL THE PARTICIPANTS in this experiment (including yourself) in each of the rounds.

We want you to guess the average amount that the participants have put into the Public Account in each round. Given that in each round the contribution could be a number between 0 and 100, your guess should also be in that interval.

We will now explain how you can earn money in this task.

\section{How can you earn money? The rule is as follows:}

If the value you guess is:

- If your guess is between 5 and 10 above or below of the actual average, you win 1 euro.

- If your guess is between 0 and 5 above or below of the actual average, you win 2 euros.

- If your guess is equal to the average contribution (an integer between 0 and 100) you will win 20 euros!!!

- otherwise, you do not win anything.

Try to make a good guess in each round because we are going to pay you according to your guess in only ONE of the rounds CHOSEN AT RANDOM.

Work out the average in each round and write the number on the form provided (Task 2).

Remember that you should write down 5 numbers, one for each round. Remember also that each number must be between 0 and 100 .

(C) 2011 by the authors; licensee MDPI, Basel, Switzerland. This article is an open access article distributed under the terms and conditions of the Creative Commons Attribution license (http://creativecommons.org/licenses/by/3.0/). 